\title{
Transforming Learning Spaces through Iterative Design to Support Inquiry-Driven Learning
}

Kimberly K. Eby, Laura A. Lukes,

George Mason University

\begin{abstract}
Through active learning classrooms (ALCs), faculty can rethink and redesign their courses to include more inquirydriven activities and experiences for students. This case study describes one large public institution's evidencebased and iterative design process for new and redesigned learning spaces. Critical elements include a cross-campus interdisciplinary team charged with planning for learning spaces of the future, the use of data to conceptualize spaces that better support teaching and learning, and the assessment of faculty-student experiences in these new learning spaces. Discussed are professional development programming and support structures for faculty that foster inquiry-driven approaches in the classroom such as faculty learning communities, workshops, and practice sessions; online and crowdsourced resources; sustained course scheduling; and institutional and departmental recognition. Also provided are recommendations for those considering campus learning-space initiatives.
\end{abstract}

Keywords: learning-space design, inquiry-driven learning, faculty development, active learning classrooms (ALCs)

\section{doi: $10.18833 /$ spur/1/2/8}

The changing landscape for higher education over the past 20 years has demanded that universities examine their current approaches to student learning and respond proactively to ensure student success. Research on cognitive science emphasizes the critical role played by students in the learning process as active participants and coconstructors of knowledge, shifting the higher education paradigm from one that was traditionally teacher-centered to one that is necessarily learner-centered (Barr and Tagg 1995; Bransford, Brown, and Cocking 2000). There is an imperative to provide access to increasing numbers of first-generation college students (Arbeit, Staklis, and Horn 2016), which requires the examination of pedagogical strategies so that potential barriers can be removed and student success can be maximized. The pragmatism of today's college students (and their families) necessitates that institutions carefully craft learning experiences that ensure the development and refinement of employerdesired competencies that will lead to success beyond the undergraduate degree. Specifically, employers seek students who can work well in diverse teams, think critically and creatively, take initiative to solve problems, and communicate effectively both in oral and written work (Hart Research Associates 2015; NACE 2016). Research has shown that high-impact practices, particularly undergraduate research, are well-documented strategies for meeting these challenges (Kuh 2008). What has received less attention, particularly now that universities are enrolling increasing numbers of students in digital and online offerings, is how our physical learning spaces should be shaped to support and facilitate approaches to learning that are more inquiry-driven (used here synonymously with the term inquiry-based).

To date, studies do not exist that directly connect classroom design and instructor choice regarding the level of the inquiry-driven curriculum. Early landmark work on the broader topic of technology-enabled active learning (TEAL; Dori and Belcher 2005) and student-centered active learning environments for undergraduate programs (SCALE-UP; Beichner et al. 2007) showed that ALCs positively influence student success (as measured by failure 
rates) and student satisfaction, but this body of work does not distinguish among instructor behavior, curriculum, and space changes. In more recent studies, classroom design has been shown to influence instructor and student behaviors (Brooks 2012) and instructor perceptions of student engagement levels (Sawers et al. 2016).

This article will discuss practices for redesigning learning spaces to better support teaching and learning. It describes how the redesign of learning spaces can facilitate faculty members' ability to include more inquiry-driven pedagogies. This case study illustrates how one large public institution is proactively using an evidence-based, iterative learning space design process to shape new and redesigned learning spaces. First, the background and context for this work are described and how active learning classrooms (ALCs) are defined on the campus of George Mason University (Mason). Second, the processes for creating these ALCs are presented. Finally, the imperative of faculty support and development is highlighted so that these new learning spaces can be leveraged to support inquiry-driven learning, with particular attention to the perceived benefits and challenges for faculty. Also provided are recommendations for other institutions that may wish to engage in similar work.

\section{Background}

George Mason University is now the largest public research university in the Commonwealth of Virginia, recently receiving a Carnegie "very high" research classification. There are approximately 36,000 students on campus, representing more than 130 countries of origin. Of those students, approximately 24,000 are undergraduates, and more than 6,000 live on campus. Just under half of the students identify as white American, whereas just over half identify with one or more ethnic minority groups. Out-of-state students represent about 20 percent of the student body.

In 2013, a strategic visioning and planning process was initiated to identify strengths and determine future directions for the university. Well underway was a large-scale undergraduate research initiative, the Students as Scholars program, which included inquiry-based and researchinfused curricular transformation grants. One outcome of the planning process was that innovative learning was identified as the first strategic goal. The aim is to "deliver a transformative signature Mason Learning Experience that is experiential, global, and technology-rich" (George Mason University 2014, 14).

At the same time, the university's one-year-old Learning Environments Group (LEG) had the charge of "advis[ing] the university on the planning and design of learning spaces for future renovation and new building projects, with an eye toward developing flexible, signature spaces that inspire students and faculty to work collaboratively on pressing intellectual and social issues." Also supporting "professional development opportunities that identify strategies, approaches, and tools for how faculty might take full advantage of our signature learning environments;" that is, discussing how the design and/or redesign of campus classrooms and informal learning spaces could be more intentional. As the LEG included students and representatives from faculty development, teaching and learning support, university libraries, student affairs, campus planning and facilities, learning space design, classroom and lab technologies, and the registrar's office, it could approach classroom "refreshes" from a facilities, technology, and-ultimately-pedagogical perspective. The creation of new and innovative physical and virtual learning spaces was integrated into the strategic plan as one of the major initiatives in service of the innovative learning goal. Thus the LEG had an increased legitimacy and a deepened sense of purpose in pursuing learning space designs that supported student learning, particularly learning that is inquiry-driven.

\section{Active Learning Classrooms at Mason}

An ALC has no single definition. Nationally, more and more institutions are building classrooms that facilitate the ability to actively engage students in learning through meaning-making, whether writing, constructing solutions, solving problems, exploring questions, addressing challenges, and/or reflecting. Often these classrooms have enhanced technological capabilities, are built for flexibility, and value the concept of learning on display. That is, there may be display capabilities for student work; the tables, chairs, and/or desks are movable; there are whiteboards or other capabilities for students to make their work, individually or within a group, visible and public. At Mason, as there have been experiments with different classroom styles and furnishings, varying types of ALCs exist. Nearly always, however, they are designed with flexibility in mind and have significant whiteboard space for students to work. For more detailed information about room layouts and features, please see our Learning Environments website (http://learningenvironments.gmu.edu/).

Three elements have been integral to the ability to intentionally redesign the university's learning spaces to better support teaching and learning. The first is the LEG. This diverse group of stakeholders has engaged in various conversations about the different types of learning spaces that best support teaching, learning, and student success.

The LEG has been fundamental to the success achieved to date. Through creating a shared vision and becoming aware of the needs and priorities of different stakeholders, a collective goal has been established and a better understanding has been achieved regarding the role of each stakeholder in achieving success. The LEG provides a place to identify constraints and address challenges. 
Co-chaired by senior members of the Office of the Provost and Campus Planning and Facilities, the LEG affords the opportunity to be more intentional and to identify and leverage possibilities that otherwise might have been overlooked.

The second element that has been central to success is the use of an iterative design process to conceptualize, assess, and redesign learning spaces. Before the LEG was established, classrooms were designed fairly independently from faculty input. Moreover, learning spaces were not intentionally assessed and feedback applied so that the most efficient and productive use of space was created. The process now includes collecting input from faculty members and students so that new designs will be responsive to their experiences with the space. These assessments are the third critical element in the university's process for learning space redesign.

The iterative design process has been important, particularly given the university's growth. Two large-scale building projects with significant numbers of classrooms are underway, providing the opportunity and arguably the imperative to deliberately consider learning space design. Prior to the iterative design process, such building projects did not capitalize on faculty and student feedback from smaller projects such as refreshes or redesigns of classrooms. Under the present framework, the advantage lies in the ability to leverage feedback from smaller redesign projects to inform larger capital projects (see Figure 1). Moreover, as classroom refresh projects surface, exploring something new becomes part of that opportunity. Thus, a commitment to exploring incremental innovations has been built and sustained; successes in these low-stakes experiments are brought to fruition in larger projects and failures are discarded so that the greatest impact can be achieved. Figure 2 maps the timeline of key milestones in the process for redesigning learning spaces to better support teaching and learning.

When the first technology-enhanced ALC opened several years ago, the faculty members teaching in that new space were part of a faculty learning community exploring strategies for teaching in that classroom. They met regularly to discuss their successes and challenges. In addition to considering the feedback from the learning community conversations, focus groups were conducted at the end of the semester to identify the attributes of the learning space that they believed were most and least valuable as they moved to a student-centered, inquiry-driven model for student learning. Several months later, a departmental move paved the way for the redesign of two classrooms; feedback from the faculty learning community informed those designs. Also piloted was a "de-centered" classroom

FIGURE 1. Iterative Design Process

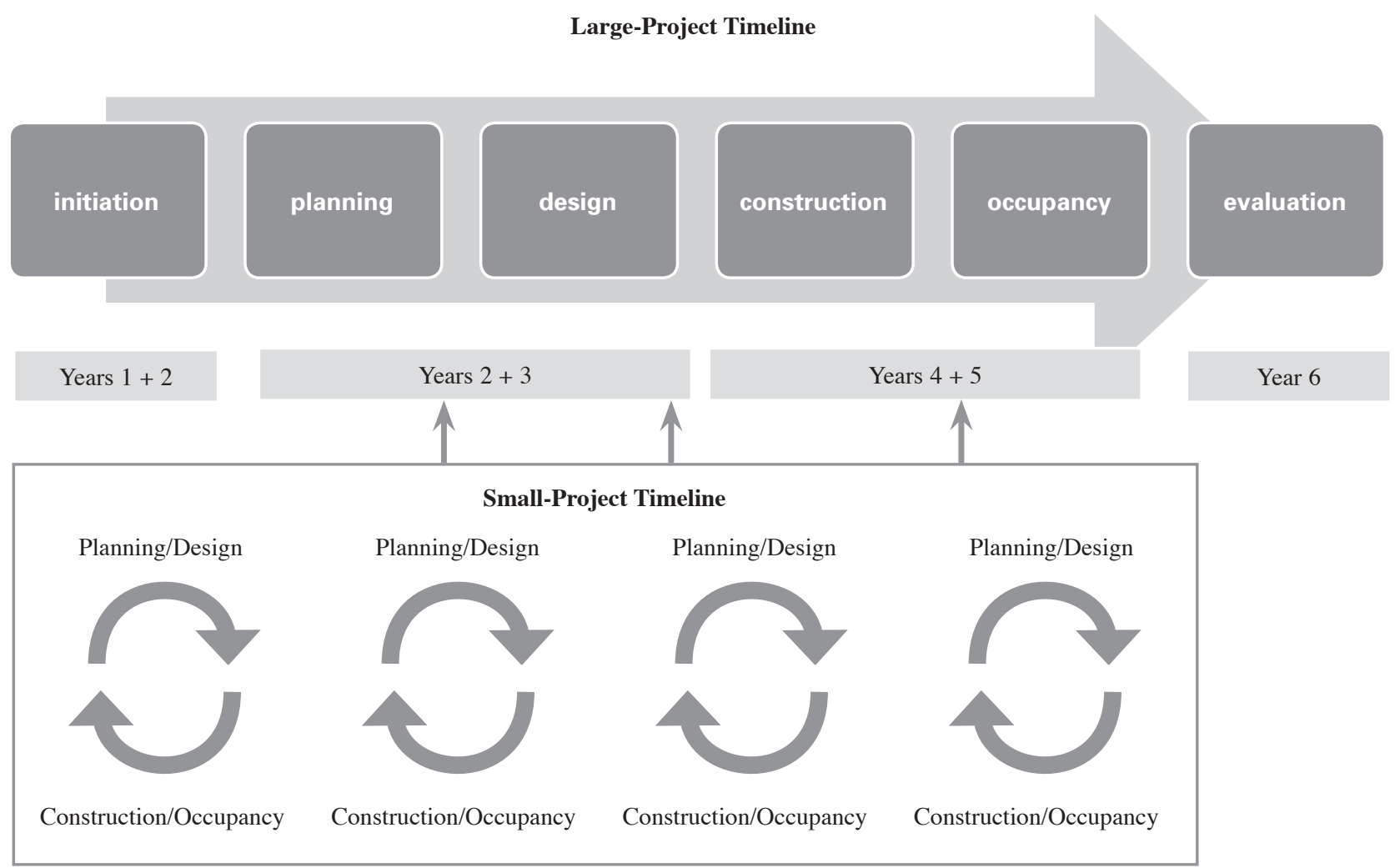

26 Scholarship and Practice of Undergraduate Research 
FIGURE 2. Timeline of Key Milestones

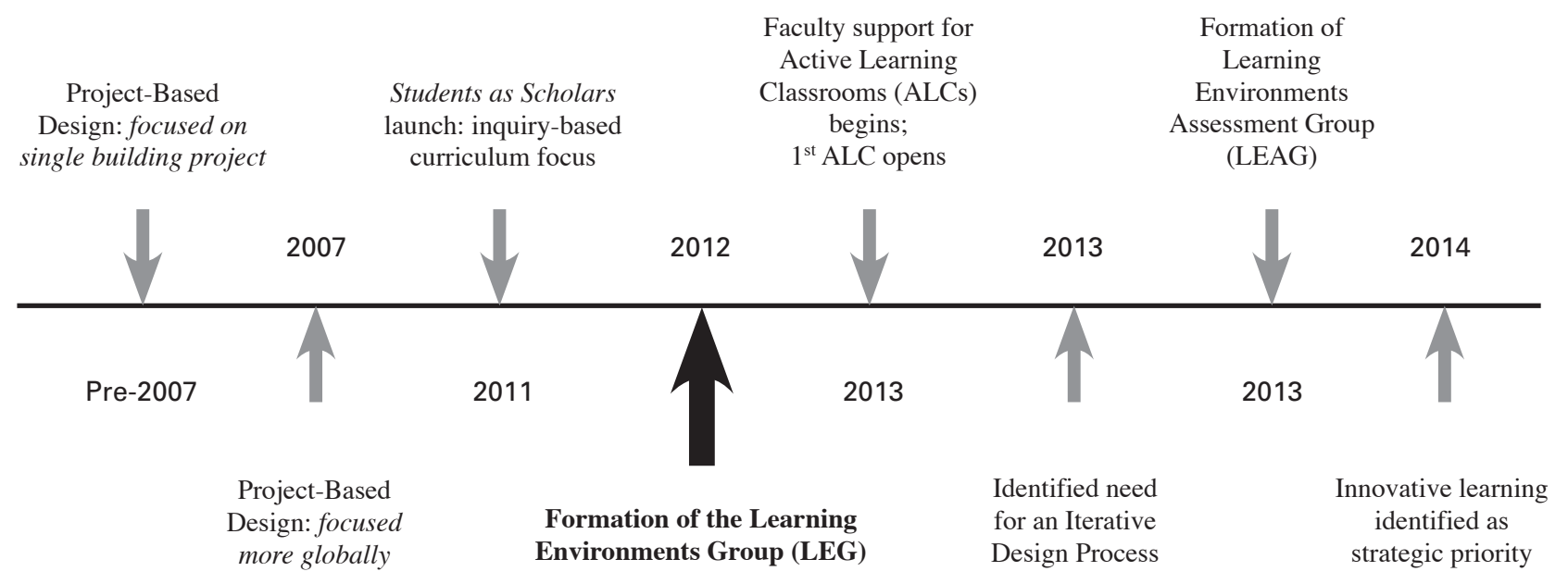

with a smaller faculty lectern off to the side-the result of faculty feedback. When those new classrooms opened, an open house was hosted for faculty teaching in those classrooms as one component of the communications plan. After the classrooms were online for one semester, data was then collected to inform the next classroom design opportunities.

Data also has been collected systematically about the faculty and student experience in these spaces through a variety of methods, including meeting notes and feedback from faculty workshops and learning communities, observations of the technology and room features used by faculty while teaching, faculty focus groups, and student and faculty surveys. A follow-up survey was sent to respondents of an initial survey sent to all faculty teaching in an ALC, who indicated that they would be willing to share more $(n=32)$. The follow-up survey listed the Council on Undergraduate Research's definition of undergraduate research-" "[a]n inquiry or investigation conducted by an undergraduate student that makes an original intellectual or creative contribution to the discipline" (Council on Undergraduate Research n.d.). The follow-up survey indicated that its questions meant this type of inquiry as well as any activities/assignments that helped students acquire the conceptual understanding or skills needed to conduct their own research (in the course or elsewhere). For example, an activity in which students practice evaluating sources would meet this definition.

When faculty discussed the perceived benefits of teaching for scholarly inquiry in ALCs, two broad themes emerged. The spaces made sharing work easy (providing boards, computer displays, arrangement of seats to foster discussion, and so forth) and facilitated student-student collaboration, strengthening the exchange of a diversity of perspectives (see photos 1 and 2). As one faculty member stated, "you can have students produce all kinds of analytical tools together on the board (Decision trees, Force Field Analysis, Fishbone, Expected Values, etc.), which can then inform and guide out-of-class research." Regarding the collaborative aspects of the spaces, one faculty member reported, "By creating group spaces in the ALC, the collaborative discussions [around critiquing research questions and designs] flow more naturally."

Accounts from other instructors showcase the relationships between inquiry-driven learning and ALCs. For example, one faculty member reported using miniprojects and class debates in the astronomy class Finding New Worlds, to provide opportunities for students to understand and articulate their exploration of a given topic. The mini-projects-exercises done in groups of two to four students - have scaffolded learning opportunities, moving from faculty-guided activities to openended exploration of a topic that culminates in student presentations of results to the class. She reported that "the space was really key to getting all students in the room engaging in groups and then being able to share what they had learned/produced with the class on whiteboards or screens." The anthropologist who teaches the course Food and Human Evolution uses inquiry-driven learning to achieve deep learning about the evolution of the human diet. In one activity, students inventory the foods that they have eaten in the past 24 hours and map them onto white boards. Using digital projection, they explore resources on the origins of the foods, and-as a class - they discuss multiple ways of categorizing the foods (such as type of food, global origins, and nutrients) so that it is clear that the foods eaten on a daily basis result from the processes of co-evolution, domestication, and globalization. As the anthropologist wrote, "I am a big fan of white boards because it gives the students an opportunity to visibly and collaboratively wrestle with challenging concepts, 
PHOTO 1. Students Working in an Active Learning Classroom

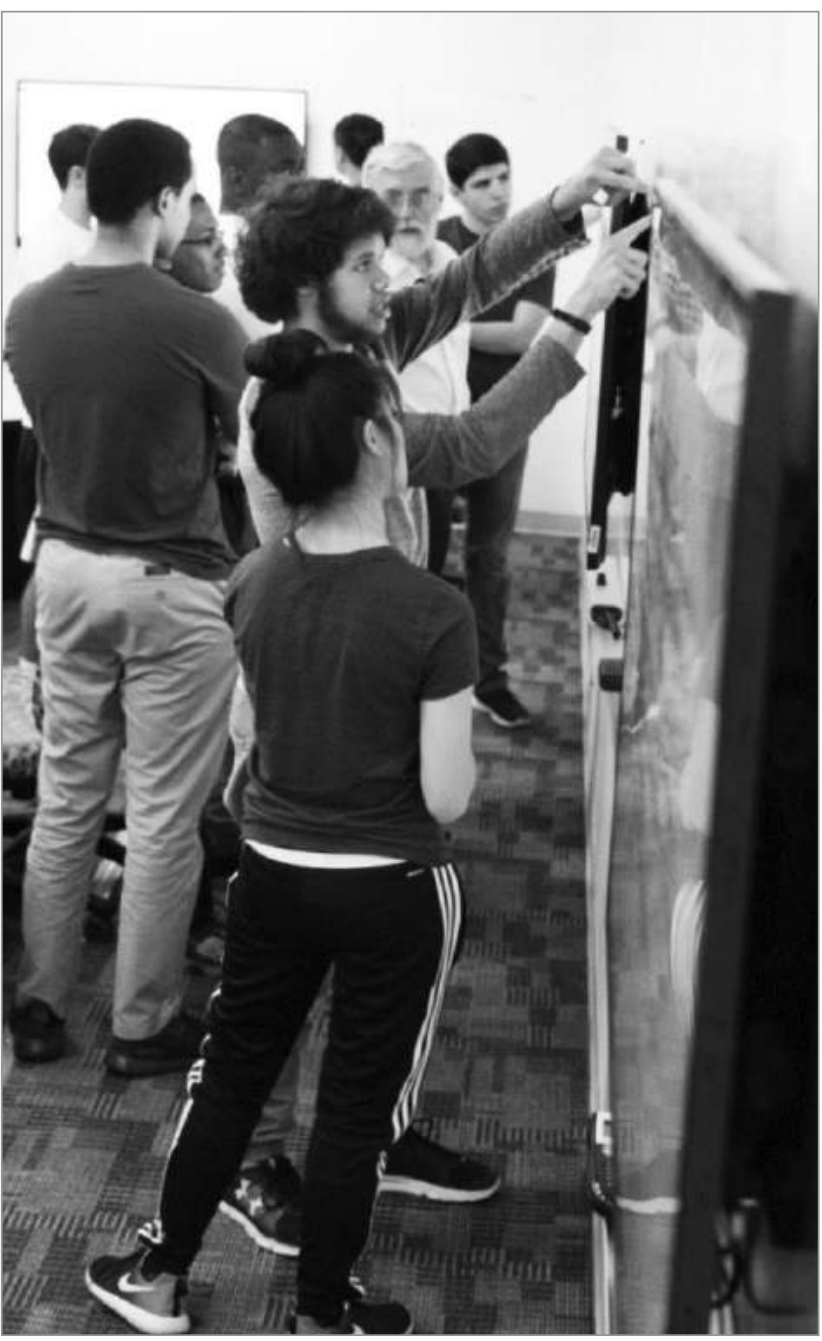

and the integrated technology in the room allows them to ask questions and find relevant resources to extend their learning." A faculty member who teaches the global and community health class "Fundamentals of Epidemiology" stated that she uses inquiry-driven learning so that students can understand the application of basic epidemiological principles via a collaborative environment that emulates the team-based approach of real-world public health. Students in this class, for example, used whiteboards in an epidemic curve exercise to graph outbreak data and determine the type of outbreak based on the shape of the curve. They also used technology to develop "factsheets" for various topics, which were then posted to the white boards. Using a gallery walk technique, students circled around the room and discussed the findings, adding to them as well as correcting them as appropriate. The faculty member noted, "The round tables to facilitate discussion and the availability of white boards to map out ideas are essential. Students who are comfortable analyzing, understanding and communicating trends in health and
PHOTO 2. Students Working in an Active Learning Classroom

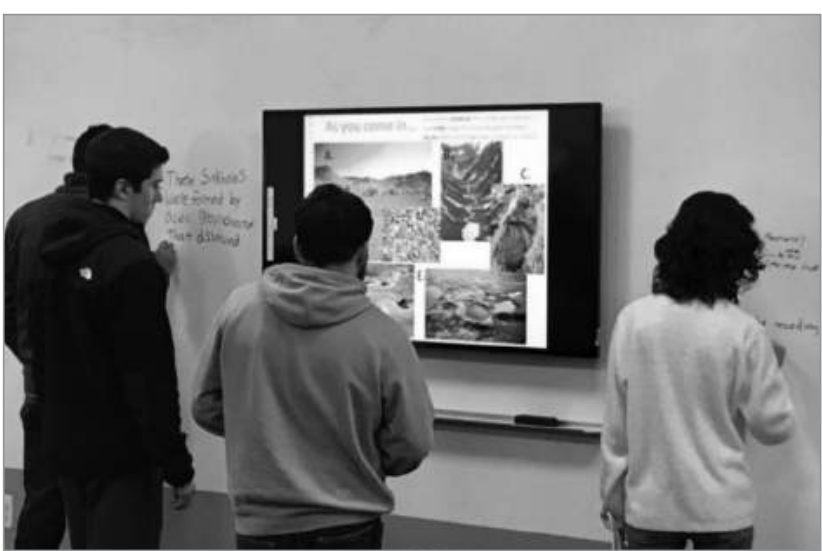

disease are in demand in the public health work force... This classroom gives them the opportunity to practice this skill in a safe, learning-focused environment."

When the surveyed faculty discussed perceived challenges of teaching for scholarly inquiry in ALCs, two broad themes emerged. There was the feeling of having insufficient knowledge or inadequate time for determining the best uses of the space for these types of activities, particularly if the course ran for only one semester. Further, faculty reported that it was difficult to provide individual feedback to students.

\section{Design Process Recommendations}

Institutions that wish to implement a similar initiative should identify and convene the diverse, critical stakeholders needed for success. Successful implementation depends on creating a shared vision across multiple stakeholders and empowering them to act on that shared vision. Designing and building spaces for inquiry-driven learning across the disciplines requires flexibility, as there is not a one-size-fits-all model. In this initiative, building relationships across campus units that did not have a history of collaboration has strengthened the ability to solve problems, share costs, and think strategically in the face of anticipated and unanticipated challenges.

Creating an institutionally appropriate version of an evidence-based, iterative design process also is recommended. Small design changes can have a large impact on generating scalable design solutions. When "small wins" are achieved, a sense of accomplishment and productivity is fostered, as well as an environment conducive to forward-thinking. Equally important, it promotes the opportunity to take strategic risks in a low-stakes way. In addition, an assessment model should be developed that captures feedback on the benefits and challenges of teaching in such learning spaces as well as on the relationship of space design to teaching and learning. 
As construction was underway on the first ALC, there was much uncertainty. Would faculty want to teach in such a space? How would they need to change their course design for such a space? Would they be comfortable with the technology or be able to leverage the capabilities of the space effectively? How would the students react? As the assessment data indicate, professional development and support for faculty teaching in these spaces was critical to help navigate this type of uncertainty, particularly if faculty need support as they develop scaffolded, inquirybased courses and curricula.

From the beginning, a variety of programming was offered that evolved in nature, scope, and goals to reflect faculty input during the iterative design process and the growth of different types of ALCs on campus. The programming consistently included five steps for faculty that other institutions may wish to include in learning space redesign efforts:

1. become familiar with the technology and capabilities offered by available ALCs;

2. (re)design courses to include active, collaborative, and inquiry-driven activities;

3. exchange experiences and strategies teaching in ALCs;

4. continue teaching in ALCs to refine teaching strategies; and

5. share expertise and be recognized for innovative teaching practices in ALCs.
These opportunities manifested in a variety of resources and events that support faculty over time (summarized in Table 1 and reflected in the recommendations below).

\section{Recommendation: Faculty Learning Communities, Workshops, and Practice Sessions}

As McArthur (2015) noted, instructors who can function in the fluidity of ALCs may experience higher student learning gains, and those who feel hampered by such spaces may see less progress in student learning. To prepare instructors to teach in these spaces successfully, professional development activities need to include more explicit directions and ways that faculty can leverage the features of these spaces to engage students in inquiry and independent scholarship. In the university's ongoing faculty learning community (FLC), instructors teaching in these spaces meet every few weeks to practice with technology, share insights, and exchange inquiry-based teaching strategies. For instructors new to teaching in these spaces, the FLC provides a safe space to ask questions and try out ideas. Because the FLC cohorts consisted of both new and returning faculty, an informal mentoring community was created that further prepared new faculty to teach in the space.

For institutions looking to adopt or adapt the model described in this article, inviting faculty to participate who have had varying levels of experience teaching in ALCs

TABLE 1. Faculty Professional Development Opportunities Related to ALCs

\begin{tabular}{|c|c|}
\hline Faculty opportunity to... & Faculty support programming \\
\hline $\begin{array}{l}\text {...become familiar with } \\
\text { the technology and } \\
\text { affordances the available } \\
\text { ALCs offer }\end{array}$ & $\begin{array}{l}\text { ALC open-house events; ALC orientation and practice days; } \\
\text { ALC workshop day }\end{array}$ \\
\hline $\begin{array}{l}\text {...(re)design courses to } \\
\text { intentionally include } \\
\text { active, collaborative, and } \\
\text { inquiry-driven activities }\end{array}$ & ALC workshop day; Course (re)Design Academy \\
\hline $\begin{array}{l}\text {...exchange experiences } \\
\text { and strategies teaching } \\
\text { in ALCs while teaching } \\
\text { in the ALCs }\end{array}$ & $\begin{array}{l}\text { Faculty Learning Community meetings every few weeks; creation of } \\
\text { Learning Environments Group website } \\
\text { (http://learningenvironments.gmu.edu) }\end{array}$ \\
\hline $\begin{array}{l}\text { ALContinue teaching in } \\
\text { ALC to refine teaching } \\
\text { strategies }\end{array}$ & $\begin{array}{l}\text { Three-semester guarantee (for select ALCs, working with registrar's } \\
\text { office to facilitate improved matching of faculty teaching approaches } \\
\text { to classroom design) }\end{array}$ \\
\hline $\begin{array}{l}\text {...share expertise and } \\
\text { be recognized for } \\
\text { innovative teaching } \\
\text { practices in ALCs }\end{array}$ & $\begin{array}{l}\text { Faculty Learning Community meetings; invited presentations for } \\
\text { campus Innovations in Teaching \& Learning conference; support to } \\
\text { conduct/present ALC scholarship of teaching and learning results at the } \\
\text { National Forum for Active Learning Classrooms; letter of support from } \\
\text { associate provost to department chairs regarding innovative work and } \\
\text { teaching evaluations }\end{array}$ \\
\hline
\end{tabular}


is recommended. As faculty returning to teaching in the space were more comfortable with their curriculum, many also chose to engage in scholarship of teaching and learning projects to formally study the effects of their innovative teaching practices on student learning and success. Based on feedback and recurring challenges in course design, a Course (re)Design Academy was held, where faculty received more explicit guidance and high-touch support in planning and designing their course in ALCs. Additional academies will be held throughout the academic year. In considering support for faculty, it is advisable to provide course redesign workshops and space/technology orientations for faculty before they teach in an ALC, as well as faculty learning communities during their coursework in ALCs.

\section{Recommendation: Online and Crowdsourced Resources}

By the fourth cohort of the ALC faculty learning community, a tremendous amount of feedback had been collected through focus group interviews, surveys, and cohort meeting notes, but a strategy needed to be found for sharing these insights across cohorts. The fourth cohort retained the community aspect of cohort meetings but shifted focus to faculty participants as leaders and experts in teaching in ALCs, providing an opportunity for faculty to compile their feedback with past faculty feedback to create theme-based tip sheets. These curated tips can be shared with any faculty interested in teaching in such spaces. In a parallel effort, as more ALCs were designed and interest in teaching in these classrooms grew, the Learning Environments website (http:// learningenvironments.gmu.edu) was created as a resource for faculty members and students. In addition to highlighting and describing the university's signature learning spaces, the website provides information about the experience of teaching and learning in these spaces, links to the Stearns Center for Teaching and Learning (http:// stearnscenter.gmu.edu) that has relevant teaching strategies, and content related to the design of learning spaces and related scholarship. Such web resources can assist the broader faculty community to thrive. Other institutions can build and/or link to similar types of resources.

\section{Recommendation: Sustained Course-Scheduling Access to ALCs}

To continue faculty motivation and ensure long-term success, faculty also need to teach in such spaces for at least two to three consecutive course offerings, so they may gain comfort and mastery in strategies for teaching in ALCs and pursue curriculum development. For one ALC, a proposal process and management of teaching schedules initially guaranteed that faculty could teach in the space for three semesters; however, this proved to be an unsustainable model as the number of ALCs increased. Currently, options to improve ongoing faculty access to
ALCs are being explored with the registrar's office. Other institutions may wish to establish a collaborative understanding between the registrar's office and departments to ensure that faculty have continual access to ALCs for teaching, particularly if they are building a course around specific features of ALCs.

\section{Recommendation: Institutional and Departmental Recognition}

The role of institutional and departmental support for faculty to engage in innovative teaching practices is also important. For example, some lower instructor evaluation scores from students in the ALCs caused concern for faculty, as these had potential implications for annual review, promotion, and tenure. In response, the associate provost for faculty affairs and development sent a letter to the department chairs of faculty teaching in one ALC, explaining the value of the faculty efforts to include inquiry-driven activities and the normalcy of lower student evaluations of teaching as faculty tried innovative strategies in their teaching. This step helped to decrease the likelihood that faculty would be penalized for participating in innovative practices. Faculty teaching in these spaces are also invited to serve as community leaders, sharing their ALC experiences and inquiry-based pedagogy expertise at the university's annual Innovations in Teaching \& Learning conference.

\section{Conclusions}

Learning spaces can be effectively transformed into ALCs that support inquiry-driven activities in the classroom. To take full advantage of this opportunity, critical elements such as feedback from diverse stakeholders, data-informed design, faculty support initiatives, and an assessment system must be present both in the design and evaluation of these learning spaces and in the support of faculty and student success. The challenges faced by institutions require a closer look at the types of learning experiences that will best serve students through facilitating deep learning and preparing them for success after graduation. As the experiences described here demonstrate, space can facilitate or hinder the choices of faculty regarding incorporation of inquiry-driven approaches into courses and curriculum. Although space matters, professional development that supports faculty through the course redesign and ongoing teaching processes is critical so they may use these transformed learning spaces most effectively. The relationship among space design, instructor practice, and inquirydriven approaches requires ongoing exploration.

\section{Acknowledgments}

The authors gratefully acknowledge LEG co-chair Laura Manno, other LEG members, and the Office of Institutional Research and Assessment for their commitment to building and assessing flexible, innovative learning spaces at Mason. 


\section{References}

Arbeit, Caren A., Sandra Staklis, and Laura Horn. 2016. New American Undergraduates: Enrollment Trends and Age at Arrival of Immigrant and Second Generation Students. Washington, DC: National Center for Education Statistics. Accessed March 14, 2017. https://nces.ed.gov/pubsearch/pubsinfo. asp?pubid=2017414

Barr, Robert B., and John Tagg. 1995. "From Teaching to Learning: A New Paradigm for Undergraduate Education." Change: The Magazine of Higher Learning 27(6): 12-26. doi: 10.1080/00091383.1995.10544672

Beichner, Robert J., Jeffrey M. Saul, David S. Abbott, Jeanne J. Morse, Duane L. Deardorff, Rhett J. Allain, Scott W. Bonham, Melissa H. Dancy, and John S. Risley. 2007. "Student-Centered Activities for Large Enrollment Undergraduate Programs (SCALE-UP) Project." In Research-Based Reform of University Physics, ed. Edward F. Redish and Patrick Cooney, 1-42. College Park, MD: American Association of Physics Teachers.

Bransford, John D., Ann L. Brown, and Rodney R. Cocking. 2000. How People Learn: Brain, Mind, Experience, and School. Washington, DC: National Academy Press.

Brooks, D. Christopher. 2012. "Space and Consequences: The Impact of Different Formal Learning Spaces on Instructor and Student Behavior." Journal of Learning Spaces 1(2). Accessed August 4, 2017. http://libjournal.uncg.edu/jls/article/ view/285/275

Council on Undergraduate Research. n.d. "Frequently Asked Questions." Accessed October 31, 2017. http://www.cur.org/ about_cur/frequently_asked_questions/

Dori, Yehudit J., and John Belcher. 2005. "How Does TechnologyEnabled Active Learning Affect Undergraduate Students' Understanding of Electromagnetism Concepts?" Journal of the Learning Sciences 14: 243-279. doi: 10.1207/s15327809j1s1402_3

George Mason University. 2014. Strategic Plan 2014-2024. Accessed March 10, 2017. http://strategicplan.gmu.edu/wp-content/uploads/2013/07/GMU_Strategic_Plan_Web.pdf

Hart Research Associates. 2015. Falling Short? College Learning and Career Success. Selected Findings from Online Surveys of Employers and College Students. Washington, DC: Association of American Colleges and Universities. Accessed March 7, 2017. http://aacu.org/leap/public-opinion-research/2015survey-results

Kuh, George D. 2008. High-Impact Educational Practices: What They Are, Who Has Access to Them, and Why They Matter. Washington, DC: Association of American Colleges and Universities.

McArthur, John A. 2015. "Matching Instructors and Spaces of Learning: The Impact of Space on Behavioral, Affective, and Cognitive Learning." Journal of Learning Spaces 4(1): 1-16.
National Association of Colleges and Employers [NACE]. 2016. "Job Outlook 2016: Attributes Employers Want to See on New College Graduates' Resumes.” Accessed March 16, 2017. http:// www.naceweb.org/s11182015/employers-look-for-in-new-hires. aspx?terms $=\mathrm{JOb} \% 20$ Outlook $\% 202016$

Sawers, Kimberly M., David Wicks, Nyaradzo Mvududu, Lane Seeley, and Raedene Copeland. 2016. "What Drives Student Engagement: Is It Learning Space, Instructor Behavior, or Teaching Philosophy?" Journal of Learning Spaces 5(2): 26-38.

\section{Kimberly K. Eby}

George Mason University, keby1@gmu.edu

Community psychologist Kimberly K. Eby joined the George Mason University faculty in 1996, receiving the university's Teaching Excellence Award in 2002. Her professional interests include violence and gender issues, leadership, organization change, and collaboration and community-building in a variety of contexts. She leads the university's efforts to cultivate a culture of faculty excellence in teaching, research, and service through conceptualizing faculty support across faculty roles, ranks, and career stages. Eby collaborates with other campus leaders on institution-wide curricular, leadership, and change initiatives, including the university's Learning Environments Group (LEG), Students as Scholars program, and various diversity and inclusion efforts. She previously served for nine years as the director of the Center for Teaching and Faculty Excellence and the associate provost for faculty development, providing programming, consultations, and professional development support to faculty and graduate students with an emphasis on teaching and learning.

Geologist and geoscience education researcher Laura A. Lukes is assistant director of George Mason University's Stearns Center for Teaching and Learning. Her research focuses on how learning environments, teaching practices, and beliefs influence the strategies and tactics used by students to manage their own learning in classroom settings (self-regulated models of learning). An award-winning educator, Lukes provides training for and actively collaborates with faculty and graduate students in incorporating active learning methods into their classrooms. Prior to joining the Stearns Center, she was an Albert Einstein Distinguished Educator Fellow in the National Science Foundation's Office of Polar Programs. She has served as president of the Geoscience Education Research Division of the National Association of Geoscience Teachers and chair of the Education Committee of the Geological Society of America. 